\title{
Formative feedback as grammar teaching
}

\author{
Susana S. Fernández \& Hanne Wacher Kjærgaard \\ Aarhus University
}

\begin{abstract}
The aim of this paper is to discuss how formative feedback (FB) on written language production can complement and at times replace grammar teaching in the context of a communicative foreign language (L2) classroom. This is illustrated with results from two research projects where formative FB contributes to developing the L2 learners' grammatical awareness. In the communicative approach to language teaching, grammatical awareness is a necessary component for achieving communicative competence, but grammar is not a goal in itself. In this approach, the teaching of grammatical items is planned according to communicative needs and can either be chosen in advance, as preparation for a task (a pre-emptive approach), or take place as a reaction to production (a reactive approach). Formative corrective FB can be considered as a reactive approach to grammar teaching.
\end{abstract}

\section{Introduction}

In this paper, we aim to discuss how formative feedback (FB), i.e. "information communicated to the learner that is intended to modify his or her thinking or behavior to improve learning" (Shute 2008: 153), on written language production can complement and at times replace grammar teaching in the context of an L2 classroom. In a communicative approach to language teaching, grammar is not an objective in itself but a means to develop communicative competence, that is, the ability to communicate adequately in a number of different communicative contexts. In this approach, the teaching of grammatical items is planned according to communicative needs and can either be chosen in advance, as preparation

Ken Ramshøj Christensen, Henrik Jørgensen \& Johanna L. Wood (eds.). 2019.

The Sign of the V-Papers in Honour of Sten Vikner. Dept. of English, School of Communication \& Culture, Aarhus University, pp. 169-183, doi:10.7146/aul.348.94. (C) The author(s). 
for a task (a pre-emptive approach), or take place as a reaction to production (a reactive approach) (Nassaji 2015). In this sense, FB constitutes a reactive approach to grammar teaching.

The role of FB for language learning has been widely discussed in the literature and, although some voices have been skeptical of its potential for promoting learning, there is consensus today regarding the positive qualities of timely and adequate formative FB (Bitchener \& Ferris 2012).

In order to illustrate the use of FB for contextualized grammar teaching, we present results from two research projects in which formative FB contributes to developing the L2 learners' grammatical awareness. In the communicative approach to L2 teaching, grammatical awareness is a necessary component for achieving communicative competence, as research has shown that an explicit attention to form (in this case, grammar) promotes learning (Nassaji \& Fotos 2011). One of the projects focuses on 8th grade English teaching in the Danish lower secondary school (Kjærgaard 2018) and the other one is situated in the context of university level Spanish (Fernández in preparation). Both cases have in common a systematic approach to formative FB with the support of technology and a strong component of interactivity. The article will discuss some results, including both successes and challenges, and will point out future perspectives.

The article starts by shortly introducing the literature about grammar teaching within the framework of SLA-studies (section 2), followed by an equivalent overview of the literature about formative FB (section 3). Once the framework for both grammar and FB has been established, sections 4 and 5 present the two case studies with the aim of exemplifying how a connection can be made between grammar teaching and FB provision. In section 6 , some conclusions will be drawn from the two cases, which can lead to further research.

\section{Grammar teaching in the Second Language Acquisition (SLA) literature}

During the 20th century, positions among SLA scholars and practitioners fluctuated greatly regarding the role of explicit grammar teaching in the L2 classroom. The first great question was whether grammar should be taught at all or whether it should rather be acquired implicitly while communicating in the target language. The extreme positions are illustrated by two widely spread methods: the grammar-translation method on one side 
and the natural approach on the other. In a sort of pendulum movement, the controversy seemed to be resolved, at least for some, in a middle position manifested in the communicative approach to language teaching, as we will see in the following paragraphs.

The classic grammar-translation method, which has in fact been used for many centuries and to some extent is still practiced today, is probably the clearest example of a form of language teaching that gives a central role to the presentation of grammatical elements (especially morphology and syntax). In this method, grammar teaching is done through systematic and atomized grammar lessons introducing one grammatical phenomenon at a time, in an order based on complexity. In the SLA literature, this approach to grammar has been given the name of "focus on forms" (Long 1991). The combination of grammar lessons where rules are explained with grammar exercises such as 'fill in the blanks exercises', followed by more free practice, has been a frequent procedure in the language classroom and has been called PPP (present, practice, produce). It originates from a view of language learning as skill learning (DeKeyser 1998), where 'practice makes perfect'. It has characterized approaches to language teaching such as the audiolingual method, where repeated, mechanical exercising is central.

At the opposite side of the spectrum, we find initiatives proscribing explicit grammar explanations from the classroom. Stephen Krashen's Natural Approach from the early 1980s was such an approach, intending to imitate the natural way in which children learn their first language. In his view, contact with comprehensible input through reading and listening is all we need to learn a language (Krashen 1985). This view has been termed 'focus on meaning', as no overt attention is given to the form of language, and only content is in focus.

Extensive research in L2 acquisition and pedagogy has shown that both extremes are insufficient and offer an unbalanced weighting of the different components needed to most effectively learn an L2. We know today that it is necessary to include a certain focus on grammatical forms, as this helps speed up the learning process, promote precision and, in general, obtain a higher proficiency level (Larsen-Freeman \& Long 1991). At the same time, there is evidence that points to the fact that grammar teaching is most effective when it is integrated into a communicative context rather than decontextualized (Larsen-Freeman 2001). The view of grammar teaching that attempts to combine the best of both worlds, a focus on communication (content) as well as on form (i.e. grammar structures, 
vocabulary and pronunciation), is called 'focus on form' (Long 1991). It represents a middle position between the two extremes, 'focus on forms' (the atomized, context-isolated grammar teaching from the grammartranslation method or the audiolingual method) and 'focus on meaning' (the grammarless approach from the early 1980s). See Nassaji \& Fotos (2011) for detailed overviews of this development.

\subsection{Focus on form}

Focus on form is the approach to grammar teaching that characterizes the communicative approach to L2 learning, which prevails today in large parts of the world. Most of the activities in a communicative classroom aim at promoting communication in the target language, but these activities can and should be combined with others that focus on the grammatical elements, vocabulary items or pronunciation features that are necessary to communicate in the situation in question.

Here, grammar teaching does not necessarily consist of the traditional grammar lesson, with the presentation of a grammatical rule followed by grammar exercises. Instead, a short grammatical explanation can be given as a preparation for a communicative activity. This can be considered a 'pre-emptive' approach, i.e. an anticipation of the language items that are needed to be able to execute a task in the L2. For instance, the past tense can be briefly reviewed before a task consisting of talking about what the students did the previous weekend or the future tense can be introduced to be able to talk about plans for the coming holidays. The opposite approach is termed 'reactive' (Nassaji 2015). It consists of corrective FB given after an activity is over, e.g. when the teacher comments on the most common errors from a finished task. Both in the pre-emptive and reactive approaches, several grammatical items can be addressed in the course of the same lesson. This is called 'extensive' grammar teaching, as opposed to the classical 'intensive' grammar teaching, where longer time is used for each topic and therefore only one topic is normally presented in one class (Ellis 2006).

Despite its name, the approach of "focus on form" has more than just form in focus. Explanations about form are inseparable from explanations about meaning and pragmatic function. The interplay of the three dimensions - form, meaning and function - constitutes the axis of grammar teaching within the communicative approach. So presenting, for instance, the imperfect past tense in Spanish implies working with form (the right verb endings), the meaning of this tense (representing an internal facet of a 
past situation), and its most frequent functions (e.g. presenting background information in a narration). This helps to create linguistic awareness, i.e. allows the students to understand how the target language works.

Although the SLA literature has argued for this kind of communicatively contextualized grammar teaching for a long time now, we know from teacher cognition studies (studies focusing on language teachers' knowledge and beliefs about different aspects of language teaching) (e.g. Borg 2015) that teachers find it difficult to implement this kind of grammar teaching. They often fall back on the more familiar 'focus on forms' that they themselves experienced as language learners. In fact, numerous studies show that teachers' reasons for how they teach grammar are not necessarily related to a belief that their grammar teaching promotes learning, as many other factors are at stake: examination requirements, time constraints, learners' expectations and proficiency level, and available materials, among others. All this makes innovation in grammar teaching and a movement towards a grammar based on communicative needs notoriously slow.

\section{Written corrective FB}

FB can be defined as "information by an agent [...] regarding aspects of one's performance or understanding [...] FB is thus a consequence of performance" (Hattie \& Timperley 2007: 81), and it serves the purpose of "[reducing] discrepancies between current understandings and performance and a goal" (Hattie \& Timperley 2007: 86). In our context, then, it is information by a teacher or fellow students on a student's written performance with the purpose of reducing the gap between the students written performance and the goal of the relevant level of education.

That this article concerns itself with mainly written FB on written language is not incidental: We know that written language has a higher degree of permanence, which allows for more attention and noticing than oral FB. There is more time for planning for the student when writing, for the teacher when providing FB (Golonka et al. 2014) and for the student when engaging with the FB (Bitchener \& Storch 2016).

The research on FB has categorized various types of FB, one major distinction being oral and written. In this article, only written FB will be in focus, and written FB is usually taken to be both FB that is written and FB on written production. However, in our understanding, FB on written production can also, as in parts of case 2 below, be oral. Most often, teachers are the providers of FB, but peer FB is a viable type of FB (for pros and cons, see Yu \& Lee 2016), especially when students are at an 
educational level where they have the appropriate metalanguage - be it for textual aspects or for purely linguistic aspects.

FB can be categorized along four different coexisting continua as illustrated in Figure 1. The use of continua indicates that it is not always an either/or, but rather a question of degrees:

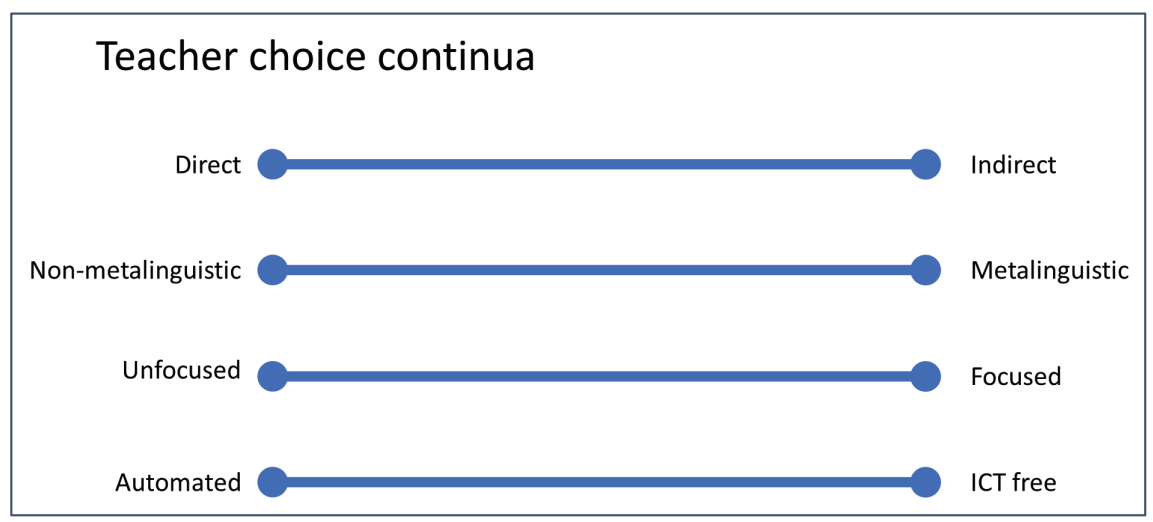

Figure 1: Illustration of the four continua characterizing a teacher's written corrective FB choices (Kjærgaard 2018) (ICT = Information and Communications Technology)

In terms of the first continuum, FB can be direct, i.e. the teacher replaces the student's error with a correct form, or it can, e.g. through provision of explanations, codes, or just a highlight indicating a location, move towards being indirect (Ellis 2008). The second continuum concerns itself with the degree to which the FB uses metalinguistic terms (Ellis 2008): Whether no metalanguage is used; whether it just provides an error code, e.g. " $\mathrm{T}$ " for tense; or whether it introduces a (new) metalinguistic term along with an explanation and/or examples. Third, FB is characterized according to whether it is focused or unfocused, i.e. whether foci are selected beforehand or when the teacher starts her actual FB provision, or whether every problem in the text is addressed (Ellis 2008). The final continuum described above concerns the degree to which technology is used in the provision of FB, and it ranges from automated FB ( $\mathrm{Li} 2016$ ) over the use of dedicated programs and comments in e.g. Microsoft Word (Hamel et al. 2016) to no use of technology at all.

Which concrete combination is most appropriate in a given situation depends on many factors. Some of them can be related to a teacher's 
general approach, but in most cases, there is no one "best practice" to cover all instances, as many issues need to be taken into consideration:

- Although we know that indirect FB is generally advantageous for student learning as it can be seen as a form of problem solving with high levels of involvement (Bitchener \& Knoch 2009), it makes little sense in relation to e.g. grammar or vocabulary errors where the student lacks the knowledge to be able to self-correct (Bitchener \& Knoch 2008); in these instances, direct FB with explanations is more appropriate and useful.

- Also metalinguistic FB can provide the student with clues for self-correction in a more problem-solving approach (Ferris 2011). However, the student needs to be familiar with the metalanguage used, and this will determine the appropriateness of the type of metalinguistic FB used.

- In general, research tells us that an unfocused approach is seldom appropriate, both because it discourages students and leaves them little to focus on in future papers (Hartshorn et al. 2010); however, this depends on the educational and language level of the students (Bitchener \& Storch 2016).

- Finally, whether a choice of technology is possible will depend, in many cases, on organizational availability rather than teacher choice.

\section{Case 1: IT-supported written corrective FB in 8th grade English}

In this 8-month intervention study, three lower secondary school teachers and their classes were involved in a two-pronged intervention aiming at incorporating what is known from research to be good practice and at introducing a computer program intended to support teachers' systematicity in the provision of FB as well as students' learning outcome of teacher FB. Teachers' practice prior to the intervention consisted in slightly unsystematic FB on issues that the teacher happened to stumble across, just as, in many cases, direct FB was given. The students were not asked to revise or engage with teacher FB in any way.

The intervention required teachers to build their own FB categories and texts in the setup of the program provided (Holmes 2009), i.e. define 
the metalinguistic categories needed in their classrooms, formulate texts to provide explanations, and potentially link these to exercises and grammar materials. In their actual FB work, teachers merely had to highlight errors, click a 'button' denoting the appropriate error category, and students would then be shown merely a highlight nudging them to revise but also giving them the option of asking for more help in two stages: 1) metalinguistic categories and 2) explanations. All this had been 'preprogrammed' in the teachers' initial category building and program. Students had to revise and resubmit and were thus provided with a more formative type of $\mathrm{FB}$, given more agency, i.e. a more active role with more control of their writing, and more scaffolding (Lantolf 2000), i.e. graduated and dialogic teacher support.

Since students were provided with individual FB addressing their specific problem, the FB provided came to be an individual grammar 'lesson'. The grammar needed by the individual student at the time when it was needed (contextualized) was in focus. This is in contrast to a whole class, decontextualized, grammar session ('focus on forms'), which would most likely address very few students' zone of proximal development (Vygotsky 1978).

The intervention thus addressed both teachers and students, and it appeared to have had a positive impact on teachers' thinking and practices concerning FB as can be seen from (1), where Teacher 1 attests to her FB becoming more precise and focused and (2), where Teacher 2 explains how decontextualized grammar teaching has been discontinued:

(1) "This button system is more like... it's just a question of pushing a button, isn't it? And then there is a brief comment. It becomes more precise because it is focused on exactly that one grammatical area"1 (Teacher 1).

(2) "It's quite interesting that we haven't opened the grammar book since you and I [...] constructed the button set" (Teacher 2).

Whether the second statement in and of itself describes an advantageous practice may be discussed, but it needs to be seen in the context of written work only, where the teachers have incorporated much of the grammar book material in the program setup. Additionally, many other grammar and language activities take place in the teaching. Also, Teacher 3 describes

1 All examples are translated by the authors from either Danish or Spanish. 
how her decontextualized grammar teaching has been diminished, and that she "wants to take her starting point in what they [the students] do".

Thus, the three teachers have come to see the provision of FB as meaningful grammar teaching.

That students felt they benefited from this type of 'grammar teaching' can be seen from the following examples of student comments:

(3) Student 1: "I learn something because I learn more about English grammar."

(4) Student 2: "I become aware of which types of errors I make so that I'm not so likely to make the same ones again."

Furthermore, despite logistical and technical obstacles during the intervention, students express having gotten a different kind of overview and help as well as better explanations available through the program used. Finally, they claim to have learned more simply due to the revision requirement and have achieved greater agency, both through having to revise and through being able to interact with the program and choose the level of scaffolding necessary.

\section{Case 2: Focus on grammar through different forms of correc- tive FB at a university level Spanish writing course}

This case deals with a 12-week writing course designed with a focus on process writing, i.e. with subsequent resubmissions of a text in response to FB. The course targeted university students of Spanish with a B2 level of proficiency with the aim of improving their writing skills in different genres. The course was highly student-centered in its design, as the students themselves were consulted about the selection of topics and text types to be practiced. The students were also assigned different roles as writers, readers, reviewers, reflective learners and team players. The course was devised as an action research project intended to test and evaluate a FB design consisting of a multimodal FB chain (see Figure 2). The types of FB selected and the general modality of the course were based on findings from language pedagogical literature about written corrective FB. The tested FB model had the following characteristics (for more detail see Fernández, in preparation): 
- Intensive FB: Each full FB cycle lasted only one and a half weeks (the cycle was repeated five times during the course). This is based on results from FB literature that show the cognitive advantages of receiving FB immediately or shortly after a text is submitted (Evans et al. 2010).

- Interactive FB: The different FB instances were links in the FB chain but never the final processing of a finished text. The students received indirect FB and were always expected to interact with the received FB in order to continue improving the text.

- ICT-based FB: Although technology was not a main focus for the project design, both text submissions and FB were delivered in Microsoft Word format and communicated via e-mail. Word's comment function and track changes were used for code correction and final direct corrections, respectively. A special Word template was used for peer FB.

- Multimodal FB: As shown in the figure below, the five different FB modalities that made up the FB chain were (in chronological order):

- Learner-centered teacher FB based on student questions (Campbell \& Fauster 2013): Each student writes 3-4 questions for the teacher to answer after reading the first submission of the text. The students receive guidelines for asking relevant questions involving both local and global aspects of the text. The students use the teacher's answers to make a new version of the text.

- Peer FB: Each student is in charge of reading a classmate's text (second version) and providing comments via a peer FB template that calls not only for corrections but also acknowledgement of the text's content and an appraisal of positive features. The students write a third version based on this FB.

○ Teacher FB with codes: The teacher reads the third version and makes indirect corrections using a code system. Again, a new version of the text is submitted.

- Final direct teacher FB: The teacher reads the fourth version of the text, corrects residual errors and makes final comments.

- Collective teacher FB: In a class session, the teacher brings up attention areas based on recurrent problems in the students' texts. As preparation for the class, students write a short self-reflection essay about the writing process. 


\section{New writing}

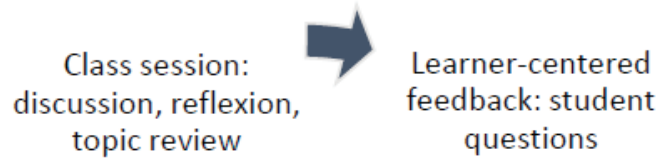

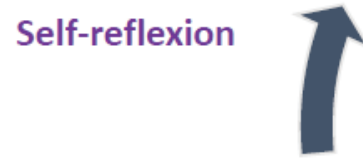

Last correction, final

comments

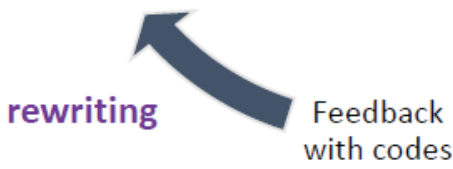

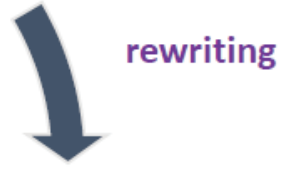

Peer-feedback

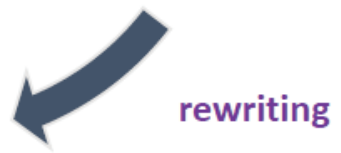

Figure 2: A multimodal FB chain in a Spanish writing course (Fernández in preparation)

The five presented FB modalities have the potential to cater for a situated focus on grammar, i.e. a focus-on-form approach as described in the communicative pedagogical literature briefly presented in section 2 . The course did not include explicit grammar teaching in the form of PPP; nevertheless, there were numerous instances during the 12 weeks of the course where grammar was directly targeted.

The first FB modality, teacher FB based on student questions, allowed students to ask questions about grammar issues (among other things) that they were in doubt about and to receive metalinguistic explanations from the teacher, as shown in the following example:

(5) Student question: Is the use of the future tense correct?

Teacher answer: In the aforementioned example "hayan desaparecido" there should be a perfect future in the indicative mood. In "habrán" the future tense is right but not the plural, as "haber" should never be used in the plural form according to standard Spanish rules. The form "desaparecieren", which is a future subjunctive (and as such has 
fallen out of use) is not correct. We do not need a subjective form in this context.

The second FB modality, indirect FB with codes, made the students revise errors based on a marking of error types, many of them grammar errors, as illustrated in (6). The students needed to focus their attention on grammar in order to revise the text.

(6) MV - "mood": error in modus selection between indicative and subjunctive

SIN - "syntax" - it can be a problem with a determiner (article, possessive or demonstrative determiner, etc.) or lack of agreement in gender and number in a noun phrase, or an incomplete sentence

In peer FB, the students exerted a double focus on grammar: when reading the classmate's text and making comments on grammar issues, and when processing the FB report they received on their own text. (7) illustrates peer FB with an explicit grammatical focus:

(7) Some sentences are too long, and they should be shorter and more precise. There are several examples of lacking agreement between subject and verb. You should focus on subject number (singular/plural).

Last but not least, the collective FB session can be seen as a contextualized grammar lesson, as each of the five practiced genres called for different grammatical foci based on the students' problems with the text (e.g. the narrative text called for a focus on tenses and mood, while the argumentative text required a review of connectors).

Throughout the course, a situated focus on form based on communicative needs contributed to the students' grammatical improvement without a single traditional grammar lesson. All feedback modalities in the chain were evaluated positively by the students as regards learning opportunities.

\section{Discussion and conclusion}

In the course of this article we have argued that grammar teaching can be and has been taught in different ways, explicitly or implicitly, in context or in isolation. Today's understanding of its value for promoting language 
acquisition favors an approach that relates grammar to meaning and to the communicative situation in question. One way of achieving this, though not the only one, is by tapping into the opportunities that different kinds of formative feedback can offer.

Having shown two examples of how written corrective FB constitutes grammar teaching, it is important to ascertain what the necessary preconditions for this are:

- The FB has to take place in a focus-on-form context

- The FB has to engage and involve students, providing them with agency (Lee 2017)

- The FB has to take into account student level (e.g. the model applied in case 2 could hardly be implemented in an 8th grade context) and the individual type of error

- The FB has to take advantage of the best available and viable ICT resources

We have not addressed the issue of whether students actually learn more in this form of grammar teaching rather than a more traditional one, since neither of the studies described is an effect study. The cases have proved to be successful as regards teachers' and students' perceived increase in learning, but new studies with a focus on effect are necessary, even though teaching constitutes a "wild problem" (Christensen 2006) with myriad variables, which renders cause-and-effect studies difficult.

\section{References}

Bitchener, John \& Dana Ferris. 2012. Written corrective feedback in second language acquisition and writing. London: Routledge.

Bitchener, John \& Ute Knoch. 2008. The value of written corrective feedback for migrant and international students. Language Teaching Research 12(3). 409-431. doi:10.1177/1362168808089924.

Bitchener, John \& Ute Knoch. 2009. The relative effectiveness of different types of direct written corrective feedback. System 37(2). 322-329. doi:10.1016/j. system.2008.12.006.

Bitchener, John \& Neomy Storch. 2016. Written corrective feedback for L2 development (Second Language Acquisition 96). Bristol: Multilingual Matters. 
Borg, Simon. 2015. Teacher cognition and language education: research and practice (Bloomsbury Classics in Linguistics). 2nd ed. London: Bloomsbury Academic.

Campbell, Nancy \& Jennifer Schumm Fauster. 2013. Learner-centred Feedback on Writing: Feedback as Dialogue. In Margit Reitbauer, Nancy Campbell, Sarah Mercer, JenniferSchumm-Fauster \& Renate Vaupetisch (eds.), Feedback Matters: Current Feedback Practices in the EFL Classroom, 55-68. Frankfurt: Peter Lang.

Christensen, Torben Spanget. 2006. Formativ evaluering. In Erik Damberg, Jens Dolin \& Gitte Ingerslev (eds.), Gymnasiepcedagogik, 361-382. Copenhagen: Hans Reitzels Forlag.

DeKeyser, Robert. 1998. Beyond focus on form: Cognitive perspectives on learning and practicing second language grammar. In Catherine Doughty \& Jessica Williams (eds.), Focus on form in classroom second language acquisition, 42-63. Cambridge: Cambridge University Press.

Ellis, Rod. 2006. Current issues in the teaching of grammar: An SLA perspective. Tesol Quarterly 40(1). 83-107. doi:10.2307/40264512.

Ellis, Rod. 2008. A typology of written corrective feedback types. ELT Journal 63(2). 97-107. doi:10.1093/elt/ccn023.

Evans, Norman W., K. James Hartshorn, Robb M. McCollum \& Mark Wolfersberger. 2010. Contextualizing corrective feedback in second language writing pedagogy. Language Teaching Research 14(4). 445-463. doi: $10.1177 / 1362168810375367$.

Fernández, Susana F. in preparation. Feedback interactivo y centrado en el estudiante: Un estudio de caso con estudiantes avanzados de español.

Ferris, Dana. 2011. Treatment of error in second language student writing. Michigan: University of Michigan Press.

Golonka, Ewa M., Anita R. Bowles, Victor M. Frank, Dorna L. Richardson \& Suzanne Freynik. 2014. Technologies for foreign language learning: a review of technology types and their effectiveness. Computer Assisted Language Learning 27(1). 70-105. doi:10.1080/09588221.2012.700315.

Hamel, Marie-Josée, Nikolay Slavkov, Diana Inkpen \& Dingwen Xiao. 2016. MyAnnotator: A Tool for Technology-Mediated Written Corrective Feedback. Traitement Automatique des Langues 57(3). 119-142.

Hartshorn, K James, Norman W Evans, Paul F Merrill, Richard R Sudweeks, Diane Strong-Krause \& Neil J Anderson. 2010. Effects of dynamic corrective feedback on ESL writing accuracy. Tesol Quarterly 44(1). 84-109. doi:10.5054/tq.2010.213781.

Hattie, John \& Helen Timperley. 2007. The power of feedback. Review of educational research 77(1). 81-112. doi:10.3102/003465430298487.

Holmes, Martin. 2009. Markin. Creative Technology. https:/www.cict.co.uk/ markin/index.php (14 April, 2016). 
Kjærgaard, Hanne Wacher. 2018. Technology-mediated written corrective feedback in the Danish lower secondary classroom. Aarhus: Aarhus University $\mathrm{PhD}$ dissertaion.

Krashen, Stephen D. 1985. The input hypothesis: issues and implications. London: Longman.

Lantolf, James P. 2000. Introducing sociocultural theory. In James P. Lantolf (ed.), Sociocultural theory and second language learning, vol. 1, 1-26. Oxford: Oxford University Press.

Larsen-Freeman, D \& MH Long. 1991. An introduction to second language acquisition research. London: Longman.

Larsen-Freeman, Diane. 2001. Teaching grammar. In Marianne Celce-Murcia (ed.), Teaching English as a second or foreign language, 251-285. 3rd ed. Boston: Heinle \& Heinle.

Lee, Icy. 2017. Classroom writing assessment and feedback in 12 school contexts. New York, NY: Springer Berlin Heidelberg.

Li, Li. 2016. CALL tools for reading and writing. In Fiona Farr \& Liam Murray (eds.), The Routledge Handbook of Language Learning and Technology, 461-477. New York: Routledge.

Long, Michael H. 1991. Focus on form: A design feature in language teaching methodology. In Kees de Bot, Ralph B. Ginsberg \& Claire Kramsch (eds.), Foreign language research in cross-cultural perspective, 39-52. Amsterdam: John Benjamins Publishing Company. doi:10.1075/sibil.2.07lon.

Nassaji, Hossein. 2015. The interactional feedback dimension in instructed second language learning: linking theory, research, and practice (Advances in Instructed Second Language Acquisition Research). London: Bloomsbury Academic.

Nassaji, Hossein \& Sandra S. Fotos. 2011. Teaching grammar in second language classrooms: integrating form-focused instruction in communicative context (ESL \& Applied Linguistics Professional Series). New York: Routledge.

Shute, Valerie J. 2008. Focus on formative feedback. Review of educational research 78(1). 153-189. doi:10.3102/0034654307313795.

Vygotsky, L. S. 1978. Mind in society: the development of higher psychological processes. (Ed.) Michael Cole, Vera John-Steiner, Sylvia Scribner \& Ellen Souberman. Cambridge, Mass.: Harvard University Press.

Yu, Shulin \& Icy Lee. 2016. Peer feedback in second language writing (20052014). Language Teaching 49(4). 461-493. doi:10.1017/S0261444816000161. 